\title{
The Volatility Effect: Recent Evidence from Indian Markets
}

\author{
Nehal Joshipura1, Mayank Joshipura² \\ ${ }^{1}$ Durgadevi Saraf Institute of Management Studies (DSIMS), Mumbai, India \\ ${ }^{2}$ School of Business Management, NMIMS University, Mumbai, India \\ Email: nehal.joshipura@dsims.org.in
}

How to cite this paper: Joshipura, N. and Joshipura, M. (2019) The Volatility Effect: Recent Evidence from Indian Markets. Theoretical Economics Letters, 9, 2152-2164. https://doi.org/10.4236/tel.2019.96136

Received: July 18, 2019

Accepted: August 27, 2019

Published: August 30, 2019

Copyright $\odot 2019$ by author(s) and Scientific Research Publishing Inc. This work is licensed under the Creative Commons Attribution-NonCommercial International License (CC BY-NC 4.0). http://creativecommons.org/licenses/by-nc/4.0/ (c) (i) \& Open Access

\begin{abstract}
We provide evidence of the volatility effect from the Indian markets using the universe of past and present constituents of Nifty 500 index of National Stock Exchange (NSE). The results show that the portfolio consisting of low volatility stocks outperforms the portfolio consists of high volatility stocks and the market portfolio both in absolute and risk-adjusted terms. Further, we report that the volatility effect is a distinct effect. Size, value and momentum factors cannot explain the outperformance of low-volatility stocks. The risk anomaly is robust to the choice of risk measure; however, the volatility effect is stronger than the beta effect and it implies that both systematic risk and idiosyncratic risks contribute to the risk anomaly. The low-volatility portfolio has significant exposure to growth stocks, and it differs from the value tilt observed for low-volatility portfolios in developed markets.
\end{abstract}

\section{Keywords}

Low Risk Anomaly, Volatility Effect, Sharpe Ratio, CAPM Alpha, India

\section{Introduction}

Finance theory postulates the positive relationship between risk and return. Modern portfolio theory [1] offers a model that allows investors to construct a portfolio that optimizes a risk-return trade-off consistent with risk tolerance. Capital Asset Pricing Model (CAPM) [2] establishes a positive relationship between systematic risk and return with the beta as a measure of systematic risk. To earn a higher return, one has to invest in the high-beta portfolio and assume a higher risk. The underlying assumption is that rational investor should hold a fully diversified market portfolio that has zero, firm-specific, diversifiable risk. However, most investors don't hold a perfectly diversified portfolio, especially 
those, who target to outperform the benchmark market portfolio. Therefore, they may keep the unsystematic risk for superior returns. In such cases, investors look at the total risk and may look for a reward for assuming the idiosyncratic risk.

Contrary to the strictly positive relationship postulated by asset pricing theory, empirical evidence is mounting with an inverse risk-return relationship within an asset class such as equity. While the broad positive relationship holds true across asset classes, several studies across global markets report that portfolio constructed of least volatile stocks (or minimum variance portfolio), consistently outperforms the portfolio consisting of high volatility stocks and benchmark universe portfolio on a risk-adjusted basis and most times in absolute return terms over the full market cycle. These results challenged the positive relationship between risk and expected return as proposed by classic asset pricing theories. Several academic studies of the past report flatter or even inverse risk-return relationship, contrary to the positive relationship proposed by CAPM. However, such evidence didn't receive much attention and considered more like data mining exercise. However, over the past two decades, evidence for the low-risk anomaly has been mounting and the debate transcended beyond the existence of an inverse risk-return relationship to economic and behavioural explanations that justify its likely persistence.

Our study contributes to the existing body of literature in several ways. First, the paper offers strong evidence for the low-risk anomaly in Indian equity where the portfolio of low-risk stocks outperforms both high-volatility stocks and equal weight universe portfolio in risk-adjusted and nominal terms. Second, it establishes that the low-risk anomaly is unique and size, value and momentum factors cannot explain it. Third, as per [3], the low-risk stocks have a significant tilt towards value factor and they are a proxy for value stocks but this paper shows that low-risk stocks have actually a growth tilt. The evidence is in line with the fact that while low-risk anomaly is present across global markets, the characteristics of a low-risk portfolio are different in different markets. While the low-risk portfolio has a value tilt in developed markets, it has growth tilt for emerging markets [4]. India being one of the large emerging markets, the growth tilt of low-risk portfolio in the Indian market offers further evidence to more recent work on portfolio characteristics of low (high) risk portfolios. Fourth, we also compare the strength of the volatility effect by using standard deviation and beta as risk measures and also report residual volatility effect after controlling for the beta effect. And fifth, this study offers out of the sample evidence of low-risk anomaly to some earlier studies as it covers the 15-year period starting from January 2004. It also refutes the claim that large part of out-performance of minimum variance strategy is because of the period of 2000 to 2003 and is directly linked to the aftermath of dotcom bubble [5].

We organize the rest of the paper as follows. Section 2 covers the review of the literature, and Section 3 discusses the data and the empirical model. Section 4 discusses the important results and Section 5 offers Conclusion of the study. 


\section{Literature Review}

Initial evidence on a flatter than expected systematic risk and return relation as predicted from CAPM by Sharpe [2] came from Black [6] and Fama \& French [7]. Haugen \& Heins [8] claimed that the relationship was not merely flat but negative. Further Fama \& French [7] reported a flat relationship between beta and cross-section of returns in US markets for the period of 1963-1990. Haugen \& Baker [9] [10] offer initial evidence on the inverse relationship between risk and return. More recently, Clarke, Desilva, \& Thorley [11] and Blitz \& Vliet [12] report evidence for risk anomaly using a minimum variance portfolio and simple ranking based volatility portfolios, respectively. Besides Blitz \& Vliet [12] report low beta anomaly and offer both economic and behavioral explanations as a cause of it. Ang, Hodrick, Xing, \& Zhang [13] [14] and report evidence for the negative relationship between idiosyncratic risk and return in the USA and several global markets.

Most recently, Frazzini \& Pedersen [15] report evidence for the negative relationship between risk measured by beta and return where the portfolio of low beta stocks outperforms, the portfolio consisting of high beta stocks. The study attributes out-performance of a low beta portfolio to leverage constraints faced by investors. Among others, Choueifaty \& Coignard [16] [17] [18] [19] [20] find evidence for risk anomaly.

On the one hand, evidence for risk anomaly is growing and practitioners are busy latching on to the prospect of delivering higher returns without facing higher risks, off late a few studies report the positive relationship between risk and return using different methodologies. The focus of the recent studies is on finding economic and behavioral explanations to explain or explain it away, such puzzling negative relationship between risk and return and more interestingly its persistence.

Bali \& Cakici [21] attributes the negative relationship between risk and return shown by Ang A., Hodrick, Xing, \& Zhang [13] is because of small and illiquid stocks with lottery-like payoffs. Martellini [22] shows that a positive relationship between risk and return using data consisting of only surviving stocks and therefore may suffer from survivorship bias. Fu [23] shows that the relationship between expected volatility and not the historical volatility expected returns is positive by using EGARCH models to estimate idiosyncratic volatility. Scherer [3] shows that size and value factors explain most of the out-performance of the minimum variance portfolio and low volatility stocks are just a proxy for value stocks. Poullaouec T. [5] shows that out-performance of MSCI MV index MSCI World index by $0.5 \%$ during the period of 1998 to 2010 but a large chunk of this out-performance came during 2000-20003 bearish market period post technology bubble burst. Bali, Cakici, \& Whitelaw [24] produce counter-evidence to (Ang, Hodrick, Xing, \& Zhang) [14] by developing a proxy variable MAX for lottery-like payoffs. They show that a negative relationship between idiosyncratic risk and return is for lottery-like payoffs associated such stocks. 
Turning attention to explanations of risk anomaly, we have two sets of explanations to explain risk anomaly. One based on economic reasons and market frictions and others based on behavioral biases in investing.

Baker, Bradley, \& Wurgler [17] [18] and offer some explanation for the presence and sustainability of risk anomaly. They attribute the benchmarking mandate given to institutional investors as limits to arbitrage leads to high beta-low alpha and low beta-high alpha combinations. Besides, behavioral biases such as representativeness, overconfidence, and preference for the lottery as drivers to the irrational preference for high volatility stocks, making them expensive and leads to inferior returns. Blitz \& Vliet [12] [25] highlight borrowing restrictions as reported by Black [6], a decentralized investment approach and behavioral biases such as the preference for lotteries, overconfidence, and representativeness as major factors explaining the persistence of low-risk anomaly. Bali, Cakici, \& Whitelaw [24] attribute the underperformance of high volatility stocks to investors preference for lottery-like payoffs.

We clearly see the literature gap for there are only a few studies on Indian equity with respect to the low risk anomaly. Equity returns can be attributed to various factors [7] and it is important to see that the volatility effect is independently impacting the returns. This study establishes that the low-risk anomaly in Indian stock market is unique and size, value and momentum factors cannot explain it. Scherer [3] claims that the low-risk stocks have a significant value tilt but this paper shows that low-risk stocks have actually a growth tilt in India. Poullaouec T. [5] claims that large part of out-performance of minimum variance strategy is because of the period of 2000 to 2003 and is directly linked to the aftermath of dotcom bubble. This study invalidates this claim by covering the 15-year period starting from January 2004.

\section{Data and Empirical Model}

Our universe consists of past and present constituents of NSE 500 index. We collect the data of adjusted monthly closing price, market capitalization and price-to-earnings ratio for each of the stock from the Capitaline database for the period of December 2000 to December 2018. This study primarily follows Blitz \& Vliet [10] [25] empirical model with some variation.

We construct equally weighted decile portfolios by ranking stocks based on the past three-year standard deviation of monthly returns. We construct decile portfolios such that top-decile portfolio (LV) consists of lowest historical volatility stocks and bottom-decile portfolio (HV) consists of stocks with the highest historical volatility. We calculate the excess monthly returns (return over risk-free rate) for each decile portfolio for the month following portfolio construction. We repeat this process every month. For the resulting time-series of excess returns for all the iterations, we calculate the average return, the standard deviation of returns, Sharpe ratios and CAPM style alpha and ex-post beta using equally weighted index portfolio (EWI) as the proxy for the market portfolio. We repeat 
the same process to create decile portfolios sorted using beta as a risk measure instead of standard deviation. Like standard deviation, we calculate beta for each stock using past three-year monthly returns of individual stock with the market portfolio.

We apply the following two techniques to compare the strength of volatility effect and separate it from other established effects such as size, value, and momentum: First, the study applies both Fama-French three-factor (FF) and Fama-French-Carhart four-factor (FFC) regressions to separate volatility from the other effects. For Fama-French-Carhart regression, we use IIM-Ahmedabad data library to take monthly risk-free rate and size, value and momentum factor returns data. Any exposure of the low-volatility portfolio to size, value or momentum factor gets reflected in regression coefficients of these variables and reduces alpha both in terms of its magnitude and statistical significance. Second, we deploy bivariate analysis using dependent double sort. It is a strong non-parametric technique to disentangle the volatility effect from other effects and it is robust to situations involving time-varying exposure to factors such as size, value, and momentum. In double sorting, the study first ranks stocks based on one of the control factors (size, value, momentum) and then by volatility within control factor (size, value, momentum) sorted stocks decile portfolios. We then construct volatility decile portfolios to represent every decile of control factor. For example, to control for size effect, we first sort stocks based on size and divide them into size decile portfolios. Within each size decile portfolio, we sort stocks on volatility; next, we construct a top-decile volatility-sorted portfolio such that it has $10 \%$ least volatile stocks from every size decile. Similarly, we control for the size effect. We construct other volatility decile portfolios to represent stocks of all sizes. We also applied the same technique to test the strength of volatility effect after controlling for the beta. The paper applies following statistical test to evaluate the statistical significance in difference of Sharpe ratios, one factor CAPM alphas, three-factor Fama-French alphas and four-factor Fama-French-Carhart alphas. To test the statistical significance of the difference between Sharpe ratios over equally weighted universe (EWI) portfolio for each volatility decile portfolio, we use Jobson \& Korkie [26] with Memmel [27] correction.

$$
Z=\frac{S R_{1}-S R_{2}}{\sqrt{\frac{1}{T}\left[2\left(1-\rho_{1,2}\right)+\frac{1}{2}\left(S R_{1}^{2}+S R_{2}^{2}-S R_{1} S R_{2}\left(1+\rho_{1,2}^{2}\right)\right)\right.}}
$$

Here $S R_{i}$ is the Sharpe ratio of portfolio $i, \rho_{i, j}$ is the correlation between portfolios $i$ and $j$ and $T$ is the number of observations.

The CAPM alpha is calculated using EWI return as proxy for market by using following one-factor regression.

$$
R_{p, t}-R_{f, t}=\alpha_{p}+\beta_{p, m}\left(R_{m, t}-R_{f, t}\right)+\varepsilon_{p, t}
$$

where $R_{p, t}$ return on portfolio $p$ is in period $t . R_{f, t}$ is risk free return in period $t . \alpha_{p}$ is the alpha of portfolio $p, R_{m, t}$ is market portfolio return in period 
$t, \beta_{p, m}$ is the beta of portfolio $p$ with respect to market portfolio and $\varepsilon_{p, t}$ is the idiosyncratic return of portfolio $p$ in period $t$. We use equally weighted universe as proxy for market portfolio in this study unless otherwise specified.

The three-factor alpha is calculated by adding SMB (size) and VMG (value) proxies to the regression. We add WML (momentum) proxy in addition to size and value to the regression to calculate four-factor alpha.

$$
\begin{aligned}
R_{p, t}-R_{f, t}=\alpha_{p}+\beta_{p, m} & \left(R_{m, t}-R_{f, t}\right)+\beta_{p, S M B} * R_{S M B}+\beta_{P, V M G} * R_{V M G}+\varepsilon_{p, t} \\
R_{p, t}-R_{f, t}= & \alpha_{p}+\beta_{p, m}\left(R_{m, t}-R_{f, t}\right)+\beta_{p, S M B} * R_{S M B} \\
& +\beta_{P, V M G} * R_{V M G}+\beta_{P, W M L} * R_{W M L}+\varepsilon_{p, t}
\end{aligned}
$$

where $R_{S M B}, R_{V M G}$ and $R_{W M L}$ represents the return on size, value and momentum factors in our universe and $\beta_{p, S M B}, \beta_{P, V M G}$ and $\beta_{P, W M L}$ represents betas of portfolio $p$ with respect to size, value and momentum factors in our universe.

\section{Empirical Results and Discussion}

Table 1 reports the main results for the univariate analysis for the volatility decile portfolios created based on trailing 36 months' standard deviation of monthly returns.

We can see that the annualized excess return for the LV portfolio is $10.62 \%$ and it declines as we move towards the HV portfolio. The return for the HV excess return for the HV portfolio is $-17.35 \%$. This shows that the returns decline as we move from a low-volatility portfolio to a high-volatility portfolio. The annualized standard deviation declines monotonically as we move from LV to HV portfolio with LV portfolio having the standard deviation of $19.52 \%$ vs. HV portfolio having the standard deviation of $46.28 \%$. The standard deviation of the

Table 1. Main results (Annualized) for decile portfolios based on historical volatility.

This table reports the main results of univariate analysis including excess-monthly returns, annualized standard deviation, Sharpe ratio, t-statistics

\begin{tabular}{|c|c|c|c|c|c|c|c|c|c|c|c|c|}
\hline & P1 (LV) & $\mathrm{P} 2$ & P3 & $\mathrm{P} 4$ & P5 & P6 & P7 & P8 & P9 & $\begin{array}{l}\text { P10 } \\
(\mathrm{HV})\end{array}$ & LV-HV & $\begin{array}{c}\text { EWI } \\
\text { (Universe) }\end{array}$ \\
\hline $\begin{array}{c}\text { Excess return } \\
\text { (Annualized \%) }\end{array}$ & 10.62 & 7.34 & 5.66 & 2.89 & 4.30 & 1.73 & -3.74 & -2.58 & -8.51 & -17.35 & 27.97 & 0.04 \\
\hline Standard Deviation \% & 19.52 & 24.87 & 29.66 & 30.98 & 33.08 & 34.60 & 37.13 & 39.62 & 41.66 & 46.28 & 31.81 & 33.08 \\
\hline Sharpe ratio & 0.54 & 0.30 & 0.19 & 0.09 & 0.13 & 0.05 & -0.10 & -0.07 & -0.20 & -0.37 & 0.87 & -0.03 \\
\hline $\begin{array}{l}\text { (t-value for difference } \\
\text { over Universe) }\end{array}$ & 11.43 & 10.59 & 8.97 & 6.30 & 7.89 & 3.98 & -6.99 & -4.68 & -9.97 & -11.58 & & \\
\hline Realised Beta & 0.55 & 0.73 & 0.88 & 0.92 & 0.99 & 1.04 & 1.11 & 1.18 & 1.24 & 1.35 & -0.80 & 1.00 \\
\hline Alpha (\%) & 10.60 & 7.31 & 5.63 & 2.86 & 4.27 & 1.69 & -3.78 & -2.63 & -8.55 & -17.43 & 28.00 & 0.00 \\
\hline (t-value) & 4.71 & 4.02 & 3.08 & 1.93 & 2.56 & 1.15 & -2.18 & -1.38 & -3.58 & -4.75 & 5.3 & \\
\hline Max drawdown & 0.48 & 0.59 & 0.69 & 0.70 & 0.71 & 0.74 & 0.77 & 0.77 & 0.79 & 0.81 & & 0.72 \\
\hline
\end{tabular}
showing the significance of the difference of Sharpe ratio over the universe, Realised beta and one-factor CAPM style alpha and maximum drawdown for decile portfolios constructed by sorting stocks based on standard deviation calculated using past three-year monthly returns. 
LV portfolio is just about $60 \%$ of the universe portfolio (19.52\% vs $31.81 \%$ ). Likewise, the ex-post beta for the LV portfolio is 0.55 vs. 1.35 for the HV portfolio. Both risk measures: standard deviation and beta show uniform trends, and they increase sharply as we move from LV portfolio to HV portfolio. As we use historical volatility to construct decile portfolios, one argument could be that mean reversion in volatility may cause higher ex-post volatility. However, we can see that portfolios constructed based on historical low (high) volatility continue to show low (high) resultant volatility and this shows that volatility is sticky. High excess return and the low standard deviation of LV portfolio contribute to positive Sharpe ratio of 0.54 compared to zero for the universe portfolio and -0.37 for HV portfolio. The Sharpe ratio is significantly higher (t-value of 11.43) than that of the universe. The CAPM alphas also tell the same story. The alpha for LV portfolio is $10.6 \%$ which is large and positive with the corresponding t-value of 4.71 whereas the alpha for HV portfolio is a huge $-17.43 \%$ with $\mathrm{t}$-value of -4.75 . These results show that the LV portfolio has a large and positive alpha, whereas the HV portfolio has a large but negative alpha. Both are highly significant, both economic and statistical terms but with the negative sign. The last raw reports maximum drawdown, a measure of peak-to-trough percentage fall in a portfolio. The maximum drawdown for LV portfolio is $-48.2 \%$ whereas the corresponding numbers for both $\mathrm{HV}$ and universe portfolio are $81.11 \%$ and 72.45 respectively. The difference in drawdown explains the out-performance of LV portfolio and underperformance of the HV portfolio over time. The portfolio that loses $50 \%$ of its value in a period needs $100 \%$ returns in the next period to breakeven, whereas, the portfolio that loses $75 \%$ of its value in a period needs $300 \%$ return to breakeven. The base effect plays a very important role in long term compounded returns and LV portfolio has a clear advantage here and that results in eventual out-performance.

Table 2 reports similar results as Table 1, but they are for decile portfolios sorted by beta in place of the standard deviation. The results are similar, and therefore we limit the discussion for the sake of brevity. The beta effect is much weaker than the volatility effect. For example, excess return for LV portfolio sorted by beta is $4.82 \%$ compared to $10.62 \%$ for LV portfolio sorted based on standard deviation. The one-factor CAPM style alpha for the LV portfolio is $4.8 \%$ vs. corresponding alpha of $10.6 \%$ for the standard deviation sorted LV portfolio. Similarly, the negative excess return and negative alpha of $\mathrm{HV}$ portfolio are much smaller both in terms of magnitude and statistical significance and that shows that the volatility effect is stronger than the beta effect and it implies that both systematic risk and idiosyncratic risk contribute to the out-performance of $\mathrm{LV}$ portfolio and underperformance of $\mathrm{HV}$ portfolio in absolute and risk-adjusted terms.

Panel A of Table 3 reports the three-factor and four-factor alpha for LV and $\mathrm{HV}$ portfolios. Three-factor annualized alpha for LV portfolio is $12 \%(\mathrm{t}=5.3)$ which is economically and statistically significant. The four-factor alpha for the 
Table 2. Main results (annualized) for decile portfolios based on historical beta.

This table reports the main results of univariate analysis including the table reports excess-monthly returns, annualized standard deviation, Sharpe ratio, $t$-statistics showing the significance of the difference of Sharpe ratio over the Universe, Realised beta and one-factor CAPM style alpha and maximum drawdown for decile portfolios constructed by sorting stocks based on the beta calculated using past three-year monthly returns.

\begin{tabular}{|c|c|c|c|c|c|c|c|c|c|c|c|c|}
\hline & $\mathrm{P} 1(\mathrm{LB})$ & P2 & P3 & P4 & P5 & P6 & P7 & P8 & P9 & P10 (HB) & (LB-HB) & $\begin{array}{c}\text { EWI } \\
\text { (Universe) }\end{array}$ \\
\hline Excess return (Annualized \%) & 5.04 & 5.20 & 5.1 & 1.38 & 2.32 & -0.19 & -2.50 & -6.42 & -14.39 & 0.04 & 5.0 & 11.41 \\
\hline Standard Deviation \% & 19.91 & 27.87 & 30.27 & 32.54 & 34.37 & 36.99 & 39.91 & 42.92 & 48.83 & 33.12 & 0.00 & 33.97 \\
\hline Sharpe ratio & 0.25 & 0.19 & 0.17 & 0.04 & 0.07 & -0.01 & -0.06 & -0.15 & -0.29 & 0.00 & & -0.03 \\
\hline $\begin{array}{c}\text { (t-value for difference over } \\
\text { Universe) }\end{array}$ & 7.64 & 8.46 & 8.31 & 2.83 & 5.04 & -0.43 & -5.10 & -7.08 & -10.30 & 0.00 & & \\
\hline Beta & 0.56 & 0.74 & 0.82 & 0.90 & 0.97 & 1.03 & 1.10 & 1.19 & 1.26 & 1.43 & -0.87 & -0.06 \\
\hline Alpha (\%) & 4.80 & 5.01 & 5.17 & 5.08 & 1.34 & 2.28 & -0.23 & -2.55 & -6.47 & -14.44 & 19.24 & 0.95 \\
\hline (t-value) & 2.05 & 2.51 & 2.87 & 2.79 & 0.83 & 1.53 & -0.12 & -1.55 & -2.28 & -3.86 & 3.49 & \\
\hline Max drawdown & -51.59 & -64.79 & -65.37 & -70.02 & -69.17 & -74.97 & -76.35 & -78.93 & -77.96 & -81.20 & & -72.07 \\
\hline
\end{tabular}

Table 3. Three-factor (Fama-French) and four-factor (Fama-French-Carhart) style regression analysis for volatility decile portfolios.

This table reports annualized alpha and regression coefficients for the three-factor and four-factor regressions for low-volatility and high-volatility portfolios. the results show that the positive (negative) alpha for low-volatility (high-volatility) portfolio remain high and significant and the volatility effect is a distinct effect and size, value and momentum factors cannot subsume it.

\begin{tabular}{|c|c|c|c|c|c|c|c|c|c|c|c|}
\hline \multicolumn{6}{|c|}{$\begin{array}{l}\text { Fama French style regression coefficient for top } \\
\text { and bottom decile volatility portfolios }\end{array}$} & \multicolumn{6}{|c|}{$\begin{array}{l}\text { Fama French-Carhart style regression coefficient } \\
\text { for top and bottom decile volatility portfolios }\end{array}$} \\
\hline LV portfolio & Coeff. & $t$-value & HV portfolio & Coeff. & $t$-value & LV portfolio & Coeff. & t-value & HV Portfolio & Coeff. & $\mathrm{t}$-value \\
\hline $\begin{array}{l}\text { 3-factor alpha } \\
\text { (annualized) }\end{array}$ & $12 \%$ & 5.25 & $\begin{array}{l}\text { 3-factor alpha } \\
\text { (annualized) }\end{array}$ & -0.212 & -6.57 & $\begin{array}{l}\text { 4-factor alpha } \\
\text { (annualized) }\end{array}$ & $10.37 \%$ & 4.89 & $\begin{array}{l}\text { 4-factor alpha } \\
\text { (annualized) }\end{array}$ & $-19.09 \%$ & -6.22 \\
\hline EWI & 0.58 & 24.09 & EWI & 1.22 & 35.84 & EWI & 0.6207 & 25.81 & EWI & 1.16 & 33.45 \\
\hline SMB & 0.03 & 0.73 & SMB & -0.01 & -0.12 & SMB & 0.03 & 0.60 & SMB & 0.00 & 0.04 \\
\hline \multirow[t]{2}{*}{ VMG } & -0.09 & -2.43 & VMG & 0.34 & 6.22 & VMG & -0.10 & -2.89 & VMG & 0.35 & 6.85 \\
\hline & & & & & & WML & 0.13 & 4.75 & WML & -0.17 & -4.26 \\
\hline
\end{tabular}

LV portfolio is $10.37 \%(t=4.9)$. Both three and four-factor alphas remain and that establishes that the volatility effect is a distinct size, value, and momentum factors cannot explain it. Likewise, both three-factor and four-factor alphas remain large and negative for HV portfolio at $-21.2 \%(t=-6.22)$ and $-19.09 \%(t=$ -6.22) respectively. Again, large-negative alphas for HV portfolio establishes that size, value and momentum factors cannot explain the volatility effect.

Panel-B of Table 3 reports the regression coefficients for the three-factor and four-factor regressions for the LV and HV portfolios. While the beta of an LV portfolio for three and four-factor regressions are comparable to ex-post beta reported in Table 1, we observe that the regression coefficients for size (SMB) factor are about 0.03 for both three-factor and four-factor model is statistically insignificant and it shows that LV portfolio has no exposure to the size factor. However, the regression coefficients for value (VMG) factor is for is -0.1 for 
both three-factor and four-factor regression and negative and statistically significant and the negative loading on value factor shows that LV portfolio has growth rather than value tilt. This is an interesting result, as studies from developed markets report significant value tilt for value stocks. Such negative loading also explains why the three-factor alpha for the LV portfolio is, in fact, higher than one-factor alpha. The regression coefficient for momentum (WML) factor for the LV portfolio is positive with a loading of 0.14 and it is statistically significant. This shows that momentum exposure can explain a small part of LV alpha. Analysing factor loadings of three and four-factor regressions show that LV portfolio consists of growth and winner stocks and is size agnostic. The similar analysis for HV portfolio suggests that not LV but HV portfolio has the large positive loading on value factor with the coefficient for VMG is $0.34(t>6)$ and it shows it has HV portfolio has heavy value tilt. The HV portfolio has a large negative loading on the momentum factor with a coefficient of -0.17 on WML which is highly significant. Analysis of regression coefficients shows that the HV portfolio consists of value a loser stocks and is size agnostic. We attribute insignificant exposure to size factor for both LV and HV portfolios to the heavily skewed distribution of market-cap in Indian equity markets.

Table 4 reports one-factor CAPM style alpha for decile portfolios first sorted on control variables such as size, value, momentum and beta and then sorted using volatility to ensure that the resultant decile portfolio represents each decile

Table 4. Double-sorted results.

This table reports the results of the one-factor CAPM style alpha for volatility decile portfolios controlling for size, value, momentum, and beta. This table shows that the volatility effect is robust and remains strong.

\begin{tabular}{|c|c|c|c|c|c|c|c|c|c|c|c|}
\hline \multicolumn{12}{|c|}{ Panel A: Annualized alpha from double sort on size (market capitalization) and volatility of past 3 years } \\
\hline & LV & P2 & $\mathrm{P} 3$ & $\mathrm{P} 4$ & P5 & P6 & P7 & P8 & P9 & $\mathrm{HV}$ & LV-HV \\
\hline Alpha & $9.98 \%$ & $7.89 \%$ & $4.63 \%$ & $3.86 \%$ & $1.74 \%$ & $-0.02 \%$ & $-1.93 \%$ & $-3.78 \%$ & $-7.52 \%$ & $-14.84 \%$ & $24.82 \%$ \\
\hline t-stat & 5.25 & 4.39 & 2.87 & 2.46 & 1.09 & -0.01 & -1.28 & -1.95 & -2.93 & -4.73 & 5.63 \\
\hline \multicolumn{12}{|c|}{ Panel B: Annualized alpha from double sort on value (earnings/price) and volatility of past 3 years } \\
\hline & LV & $\mathrm{P} 2$ & P3 & $\mathrm{P} 4$ & P5 & P6 & P7 & P8 & P9 & $\mathrm{HV}$ & LV-HV \\
\hline Alpha & $5.50 \%$ & $4.75 \%$ & $4.30 \%$ & $2.60 \%$ & $2.10 \%$ & $-2.50 \%$ & $1.30 \%$ & $-2.50 \%$ & $-4.85 \%$ & $-9.30 \%$ & $14.80 \%$ \\
\hline t-stat & 2.10 & 2.13 & 1.99 & 1.10 & 0.99 & -1.25 & 0.70 & -0.77 & -1.55 & -2.14 & 3.78 \\
\hline \multicolumn{12}{|c|}{ Panel C: Annualized alpha from double sort on momentum (12 month minus 1 month returns) and volatility of past 3 years } \\
\hline & LV & $\mathrm{P} 2$ & P3 & $\mathrm{P} 4$ & P5 & P6 & P7 & P8 & P9 & $\mathrm{HV}$ & LV-HV \\
\hline Alpha & $10.69 \%$ & $8.62 \%$ & $4.65 \%$ & $2.63 \%$ & $2.07 \%$ & $-0.67 \%$ & $-2.08 \%$ & $-2.39 \%$ & $-9.83 \%$ & $-13.70 \%$ & $24.39 \%$ \\
\hline t-stat & 5.24 & 4.80 & 2.83 & 1.78 & 1.36 & -0.41 & -1.36 & -1.37 & -3.99 & -4.40 & 5.28 \\
\hline \multicolumn{12}{|c|}{ Panel D: Annualized alpha from double sort on beta (past 3 years) and volatility (past 3 years) } \\
\hline & LV & P2 & P3 & $\mathrm{P} 4$ & P5 & P6 & P7 & P8 & P9 & $\mathrm{HV}$ & LV-HV \\
\hline Alpha & $3.74 \%$ & $4.08 \%$ & $2.19 \%$ & $3.47 \%$ & $1.35 \%$ & $1.14 \%$ & $-4.18 \%$ & $-1.21 \%$ & $-3.31 \%$ & $-12.88 \%$ & $16.63 \%$ \\
\hline t-value & 0.61 & 0.64 & 0.34 & 0.56 & 0.20 & 0.17 & -0.62 & -0.18 & -0.48 & -1.70 & 4.59 \\
\hline
\end{tabular}


of control variables and shows pure volatility effect after controlling for other variables. Panel A reports alphas for size-controlled volatility decile portfolios. As we can see, the alpha for the LV portfolio is $9.98 \%(t=5.25)$ which is the large-positive and statistically significant. The alpha remains positive and significant for first on four decile portfolios and eventually turns negative with large and significant negative alpha for P9 and HV portfolios. The alpha for the HV portfolio is negative $14.84 \%(t=-4.73)$ which is large and significant. This shows that the underperformance of the HV portfolio is not because of small and illiquid stocks, as argued by Bali \& Cakici [21] but it prevails after controlling for size.

Panel B reports alphas for value-controlled volatility decile portfolios. Alpha for $\mathrm{LV}$ portfolio is $5.5 \%(\mathrm{t}=2.1)$ which is still large-positive and statistically significant. Likewise, alpha for the HV portfolio is $-9.3 \%(t=2.14)$ which is large-negative and statistically significant. The alpha declines monotonically as we move from LV to HV portfolio. However, only alphas for extreme portfolios are large and significant.

Panel C reports alpha for momentum-controlled volatility decile portfolios. Here too, alpha for LV portfolio is $10.69 \%(t=5.23)$ which is the large-positive and statistically significant. The alpha for the HV portfolio is $-13.7 \%(t=-4.4)$ which is the large-negative and statistically significant. These results offer evidence for a distinct volatility effect that remains strong after controlling for size, value, and momentum factors. And even if LV and HV portfolios have time-varying exposure to size, value, and momentum factors in regression, the results from the double sort suggests that volatility effect is large, distinct and robust.

Finally, we control for the beta to see the robustness of the volatility effect and measure the implied relationship between idiosyncratic risk and expected returns. Since the volatility is the measure to total risk, systematic risk as well as idiosyncratic risk and beta measures the systematic risk, the volatility effect controlled for beta captures the relationship between the idiosyncratic risk and expected returns. In addition, it captures the relative strength of volatility and beta effect. Panel D reports that alpha volatility decile portfolios after controlling for the beta. The alpha for LV portfolio is $3.74 \%(t=0.62)$ which is economically significant but statistically insignificant. However, alpha for HV portfolio is $-12.88 \%(t=-1.7)$, it is economically significant and statically significant at $10 \%$ significance level. This shows that the volatility effect is still present after controlling for the beta, but it is much weaker and more dominant for the HV portfolio than the LV portfolio. Our results are in line with Blitz, Pang, \& Vliet [24] who report stronger volatility effect than beta effect. Our result also supports Bali \& Cakici [21] who argued that the volatility effect associated with idiosyncratic risk is because of high idiosyncratic risk stocks with lottery-like payoffs. The dominant inverse relationship between idiosyncratic risk and expected returns on the HV leg of the portfolio than the LV portfolio supports this argument. 


\section{Conclusion}

Our study offers a piece of strong evidence for the volatility effect in Indian markets. The inverse relationship between risk and returns is clear as the portfolio consisting of low-volatility stocks outperforms the market portfolio and the portfolio consisting of high-volatility stocks. The out-performance of the LV portfolio and underperformance of the HV portfolio both contribute to the volatility effect. Such an inverse risk-return relationship is present notwithstanding the choice of risk measures. However, the effect is stronger for standard deviation rather than beta as a risk measure. Both systematic risk and idiosyncratic risk contribute to the volatility effect. The portfolio of LV stocks not only outperforms in risk-adjusted terms but also in absolute returns terms. The volatility effect is a distinct effect, exposure to size, value, and momentum factors cannot explain it. Also, the low volatility portfolio has a systematic tilt towards growth and winners' stocks, whereas the high volatility portfolio has a tilt towards value and loser stocks. Both LV and HV portfolios don't show any tilt towards large or small stocks. The growth tilt of the LV portfolio differs from the value tilt observed in developed markets. Thus, while the volatility effect is universal, the characteristics of a low volatility portfolio are different for developed and emerging markets.

\section{Conflicts of Interest}

The authors declare no conflicts of interest regarding the publication of this paper.

\section{References}

[1] Markowitz, H. (1952) Portfolio Selection. The Journal of Finance, 7, 77-91. https://doi.org/10.1111/j.1540-6261.1952.tb01525.x

[2] Sharpe, W. (1964) Capital Asset Prices: A Theory of Market Equilibrium under Conditions of Risk. The Journal of Finance, 19, 425-442. https://doi.org/10.1111/j.1540-6261.1964.tb02865.x

[3] Scherer, B. (2011) A Note on the Returns from Minimum Variance Investing. Journal of Empirical Finance, 18, 652-660. https://doi.org/10.1016/j.jempfin.2011.06.001

[4] Chow, T., Hsu, J.C., Kuo, L. and Li, F. (2014) A Study of Low-Volatility Portfolio Construction Methods. The Journal of Portfolio Management, 40, 89-105. https://doi.org/10.3905/jpm.2014.40.4.089

[5] Poullaouec, T. (2010) Things to Consider When Investing in Minimum Volatility Strategies. State Street Global Advisors Asset Allocation Research.

[6] Black, F. (1972) Capital Market Equilibrium with Restricted Borrowing. The Journal of Business, 4, 444-455. https://doi.org/10.1086/295472

[7] Fama, E.F. and French, K. (1992) The Cross-Section of Expected Stock Returns. The Journal of Finance, 47, 424-465. https://doi.org/10.1111/j.1540-6261.1992.tb04398.x

[8] Haugen, R.A. and Heins, A.J. (1975) Risk and the Rate of Return on Financial Assets: Some Old Wine in New Bottles. The Journal of Financial and Quantitative Analysis, 10, 775-784. https://doi.org/10.2307/2330270 
[9] Haugen, R.A. and Baker, N.L. (1991) The Efficient Market Inefficiency of Capitalization-Weighted Stock Portfolios. The Journal of Portfolio Management, 17, 35-40. https://doi.org/10.3905/jpm.1991.409335

[10] Haugen, R.A. and Baker, N.L. (1996) Commonality in the Determinants of Expected Returns. Journal of Financial Economics, 41, 401-439. https://doi.org/10.1016/0304-405X(95)00868-F

[11] Clarke, R., Desilva, H. and Thorley, S. (2006) Minimum-Varinance Portfolio in the U.S. Equity Market. The Journal of Portfolio Management, 33, 10-24. https://doi.org/10.3905/jpm.2006.661366

[12] Blitz, D.C. and Vliet, P.V. (2007) The Volatility Effect. The Journal of Portfolio Management, 34, 102-113. https://doi.org/10.3905/jpm.2007.698039

[13] Ang, A., Hodrick, R.J., Xing, Y.H. and Zhang, X.Y. (2006) The Cross Section of Volatility and Expected Return. The Journal of Finance, 61, 259-299. https://doi.org/10.1111/j.1540-6261.2006.00836.x

[14] Ang, A., Hodrick, R.J., Xing, Y.H. and Zhang, X.Y. (2009) High Idiosyncratic Volalility and Low Returns: International and Further U.S. Evidence. Journal of Financial Economics, 91, 1-23. https://doi.org/10.1016/j.jfineco.2007.12.005

[15] Frazzini, A. and Pedersen, L.H. (2014) Betting against Beta. Journal of Financial Economics, 111, 1-25. https://doi.org/10.1016/j.jfineco.2013.10.005

[16] Choueifaty, Y. and Coignard, Y. (2008) Toward Maximum Diversification. The Journal of Portfolio Management, 35, 40-51. https://doi.org/10.3905/JPM.2008.35.1.40

[17] Baker, M., Bradley, B. and Wurgler, J. (2011) Benchmarks as Limits to Arbitrage: Understanding the Low-Volatility Anomaly. Financial Analysts Journal, 67, 40-54. https://doi.org/10.2469/faj.v67.n1.4

[18] Baker, M., Bradley, B. and Taliaferro, R. (2013) The Low Risk Anomaly: A Decomposition into Micro and Macro Effects. Working Paper. https://doi.org/10.2139/ssrn.2210003

[19] Soe, A.M. (2012) The Low Volatility Effect: A Comprehensive Look. S \& P DOW JONES Indices Paper. https://doi.org/10.2139/ssrn.2128634

[20] de Carvalho, R.L., Lu, X. and Moulin, P. (2012) Demystifying Equity Risk-Based Strategies: A Simple Alpha plus Beta Description. The Journal of Portfolio Management, 38, 56-70. https://doi.org/10.3905/jpm.2012.38.3.056

[21] Bali, T.G. and Cakici, C. (2008) Idiosyncratic Volatlity and the Cross Section of Expected Returns. Journal of Financial and Quantitative Analysis, 43, 29-58. https://doi.org/10.1017/S002210900000274X

[22] Martellini, L. (2008) Toward the Design of Better Equity Benchmarks: Rehabilitating the Tangency Portfolio from Modern Portfolio Theory. The Journal of Portfolio Management, 34, 34-41. https://doi.org/10.3905/jpm.2008.709978

[23] Fu, F.J. (2009) Idiosyncratic Risk and the Cross-Section of Expected Returns. Journal of Financial Economics, 91, 24-37. https://doi.org/10.1016/j.jfineco.2008.02.003

[24] Bali, T.G., Cakici, N. and Whitelaw, R.F. (2011) Maxing out: Stocks as Lotteries and the Cross-Section of Expected Returns. Journal of Financial Economics, 99, 427-446. https://doi.org/10.1016/j.jfineco.2010.08.014

[25] Blitz, D., Pang, J. and Vliet, P.V. (2013) The Volatility Effect in Emerging Markets. Emerging Markets Review, 16, 31-45. https://doi.org/10.1016/j.ememar.2013.02.004

[26] Jobson, J.D. and Korkie, B.M. (1981) Performance Hypothesis Testing with the Sharpe and Treynor Measures. The Journal of Finance, 36, 889-908. 
https://doi.org/10.1111/j.1540-6261.1981.tb04891.x

[27] Memmel, C. (2003) Performance Hypothesis Testing with the Sharpe Ratio. Finance Letters, 1, 21-23. 